\title{
A Construção Social da Identidade Turística: uma visão do institucionalismo organizacional
}

\author{
Mariene Cavalcante Borba de Albuquerque
} Samir Adamoglu de Oliveira ${ }^{b}$

\section{Resumo}

O ensaio objetiva estabelecer uma interlocução entre os conceitos de 'identidade organizacional', 'construcionismo social' e 'atividade turística' sob a ótica do institucionalismo organizacional, demonstrando sua complementariedade, de modo a contribuir para novas possibilidades de discussão entre esses temas. A identidade turística é fruto de processos de construção social em que o fato de uma localidade possuir atrativos que demonstrem algum potencial turístico não a confere legitimidade no campo organizacional do turismo. A identidade acontece mediante interação entre diversos atores organizacionais que compõem esse campo e recebem influências externas e internas no desenvolvimento de suas atividades. A apropriação da identidade pelos atores que formam o campo acontece gradativamente, mediante processos institucionais. Desse modo, conclui-se que: (i) a identidade turística de um local é caracterizada pelos atrativos que ele possui e que, mediante diretrizes definidas, condicionam ações e comportamentos que maximizam sua utilidade, sendo moldados pelo cenário em que estão inseridos, legitimando-se no campo organizacional de que faz parte, sobretudo pelos sentidos e significados que vão atrelando-se a ela; e que (ii) é preciso construir a identidade organizacional de um local a partir de atributos de centralidade, distintividade e durabilidade que o legitimem para, assim, ser considerado um destino turístico e impactar positivamente, possibilitando seu desenvolvimento.

Palavras-chave: Identidade do destino turístico; Institucionalismo Organizacional; Construção Social; Legitimidade; Governança turística.

\section{Abstract}

The Social Construction of Tourism Identity: a view from organizational institutionalism

The essay aims to establish a dialogue between the concepts of 'organizational identity', 'social constructionism' and 'tourist activity' from the perspective of Organizational Institutionalism, demonstrating their complementarity, in order to contribute to new possibilities for discussion between these themes. The tourist identity is the result of social construction processes in which the fact that a locality has attractions that demonstrate some tourism potential does not confer legitimacy in the organizational field of tourism. Identity happens through interaction between different organizational actors that make up this field and receive external and internal influences in the development of their activities. The appropriation of identity by the actors that form the field happens gradually, through institutional processes. Thus, it is concluded that: (i) the

a. Mestre em Administração pela Universidade Federal da Paraíba, João Pessoa, Paraíba, Brasil. E-mail: paramarienealbuquerque@gmail.com.

b. Doutor em Administração pela Universidade Federal do Paraná, Curitiba, Paraná, Brasil. Docente do Programa de Pós-Graduação em Administração na Universidade Federal da Paraíba, João Pessoa, Paraíba, Brasil. E-mail: profsamir.adm@gmail.com. 
tourist identity of a place is characterized by the attractions that it has and that, through defined guidelines, condition actions and behaviors that maximize its usefulness, being shaped by the scenario in which they are inserted, legitimizing be in the organizational field of which it is a part, above all by the senses and meanings that are linked to it; and that (ii) it is necessary to build the organizational identity of a place based on attributes of centrality, distinctiveness and durability that legitimize it, thus, being considered a tourist destination and having a positive impact, enabling its development.

Keywords: Identity of the tourist destination; Organizational Institutionalism; Social Construction; Legitimacy; Tourism Governance.

\section{Resumen}

\section{La Construcción Social de la Identidad Turística: una visión desde el institucionalismo organizacional}

El ensayo tiene como objetivo establecer un diálogo entre los conceptos de 'identidad organizacional', 'construccionismo social' y 'actividad turística' desde la perspectiva del institucionalismo organizacional, demostrando su complementariedad, para contribuir a nuevas posibilidades de discusión entre estos temas. La identidad turística es el resultado de procesos de construcción social en los que el hecho de que una ubicación tenga atracciones que demuestren cierto potencial turístico no confiere legitimidad en el campo organizacional del turismo. La identidad ocurre a través de la interacción entre diferentes actores organizacionales que componen este campo y reciben influencias externas e internas en el desarrollo de sus actividades. La apropiación de la identidad por parte de los actores que conforman el campo ocurre de manera gradual, a través de procesos institucionales. Así, se concluye que: (i) la identidad turística de un lugar se caracteriza por los atractivos que posee y que, a través de pautas definidas, condiciona acciones y comportamientos que maximizan su utilidad, moldeándose por el escenario en el que se insertan, legitimando estar en el campo organizacional del cual es parte, sobre todo por los sentidos y significados que están vinculados a él; y que (ii) es necesario construir la identidad organizacional de un lugar con base en los atributos de centralidad, distinción y durabilidad que lo legitiman, por lo tanto, ser considerado un destino turístico y tener un impacto positivo, permitiendo su desarrollo.

Palabras clave: Identidad del destino turístico; Institucionalismo Organizacional; Construcción social; Legitimidad; Gobernanza turística.

\section{INTRODUÇÃO}

A atividade turística se desenvolve a partir da procura, pelos turistas, por destinos turísticos e o que motiva as pessoas a saírem de seus locais de residência para conhecerem e desfrutarem de momentos de lazer e entretenimento são os atrativos (Cooper, Fletcher, Fyall, Gilbert, \& Wanhill, 2008). Um atrativo corresponde a um motivador do deslocamento das pessoas, sendo o desencadeador do processo turístico e está relacionado com a motivação das viagens. Os recursos ou atrativos existentes numa localidade formam os produtos turísticos que compõem um destino, oferecendo ao visitante uma experiência turística (Valls, 2006).

A gestão de destinos turísticos requer o entendimento das transformações nos locais onde a atividade turística ocorre, de forma a analisar aspectos que potencializem o aproveitamento dos atrativos turísticos, e que minimizem impactos negativos, sendo importante compreender como o processo de 
construção social da identidade turística acontece para, assim, corroborar com a legitimação desse destino, potencializando sua utilização de forma positiva e sustentável (Cooper et al., 2008).

Aquilo que nominamos "realidade", da forma como é percebida, é resultado de um processo de construção que acontece por meio das relações entre os indivíduos, a subjetividade de cada indivíduo que constrói suas relações, as representações sobre sua percepção de mundo baseadas a partir de sua experiência pessoal, e das informações que recebem da sociedade, o que vai criando elos em que o indivíduo unifica suas ações, valores e visões de mundo. A partir disso, constroem-se regras que vão se cristalizando em forma de símbolos que se institucionalizam. Os processos de institucionalização surgem, então, como resultado da legitimação e manutenção do status quo, oferecendo uma explicação e organização social acerca daquela realidade percebida e vivenciada (Berger \& Luckmann, 2003).

A formação da identidade está intimamente relacionada aos processos de construção social, pois é o momento em que o indivíduo reforça suas concepções a respeito do mundo e de si mesmo, tornando-o único e distinto dos demais. Assim, o processo de formação da identidade é um processo de construção social em que atores estão envolvidos numa relação de troca, desenvolvendo seus entendimentos de mundo (Berger \& Luckmann, 2003). A identidade organizacional, por sua vez, possui atributos de "centralidade", "distintividade" e "temporalidade", e seu processo de formação é algo construído pelas relações sociais existentes, em que atores estão envolvidos, desenvolvendo seus entendimentos de mundo, não sendo imposta aleatoriamente (Asforth \& Mael, 1996; Berger \& Luckmann, 2003). Consequentemente, a identidade turística pode ser considerada como um processo socialmente construído em que o simples fato de uma localidade possuir atrativos que demonstrem algum potencial turístico não a confere, necessariamente, legitimidade dentro do campo organizacional do Turismo.

0 institucionalismo organizacional é uma lente teórica que analisa como as pressões sociais coordenam o funcionamento de uma instituição, em que institucionalizar é tornar algo cristalizado na sociedade, considerando que suas atividades são "tomadas como certas" (taken-for-granted), confiáveis, e que há uma legitimidade em sua existência. Uma instituição está imersa em um campo organizacional que assegura essa legitimidade por meio das relações entre os atores, suas normas, punições e costumes que poderão induzir as organizações a repetirem comportamentos em busca dessa legitimidade. Além disso, há ritos cerimoniais que podem fortalecer essa legitimação (Scott, 2014).

0 setor turístico apresenta características que podem ser consideradas enquanto um contexto adequado para a realização de uma análise institucional, destacando-se a confrontação de lógicas institucionais devido à diversidade de pressões institucionais que a atividade recebe, vide questões socioculturais locais, diversidade cultural dos turistas, regulamentação de políticas públicas, ou ainda pelas novas tecnologias relacionadas à hospedagem e deslocamento, que modificam a rotina do setor. Nisso, presume-se haver uma complexidade de lógicas conflitantes e concorrentes que afetam a prática da atividade turística. Essas mudanças constantes que o mundo contemporâneo vivencia, no qual ambientes institucionais enfrentam maiores riscos e incertezas em processos de (des)institucionalização ou de mudanças institucionais têm requerido dos atores 
uma atuação perspicaz em empreender institucionalmente, intervindo nas lógicas, ou trabalhando para criar, manter ou interromper as instituições (Carrieri, Saraiva, \& Pimentel, 2008; Lok, 2010; Falaster, Zanin, \& Guerrazzi, 2017; Fong, Wong, \& Hong, 2018).

A legitimação de um destino turístico oferece possibilidades para o desenvolvimento econômico e social, pois o turismo possui características que contribuem para o crescimento econômico e, quando gerenciado por meio de políticas e ações adequadas de seus atores, contribui estruturalmente com uma localidade, complementando outros segmentos, influenciando na economia, nos setores culturais, ambientais e de infraestrutura, melhorando, assim, a vida da população residente (Cárdenas-Garcia, Sánchez-Rivero, \& Pulido-Fernández, 2015).

Nesse contexto, este ensaio teórico almeja estabelecer uma interlocução entre os conceitos de "identidade organizacional", "construcionismo social" e "atividade turística" sob a ótica do institucionalismo organizacional, demonstrando sua complementariedade, de modo a contribuir para novas possibilidades de discussão e pesquisa entre esses temas, uma vez que os estudos encontrados os têm tratado separadamente, ignorando sua íntima relação.

Ainda que se identifiquem estudos que versem essa lente teórica no Turismo a partir da ótica histórica e política (Endres \& Pakman, 2019) ou econômica (Gomes, Vargas-Sánchez, \& Pessali, 2014), poucos são os estudos que se fundamentam no institucionalismo de base sociológica (Fong, Wong, \& Hong, 2018). Dessa forma, a partir de uma seleção não-sistemática de literatura, almeja-se contribuir para com a recente disseminação e popularização da Teoria Institucional no campo científico do Turismo - algo ainda rarefeito, conforme depreende-se a partir de Falaster, Zanin e Guerrazzi (2017) e Pimentel, Carvalho, e Pimentel (2019) -, especialmente no intuito de apresenta-lo às potencialidades dessa que é a abordagem dominante nos estudos das organizações e da gestão, na Administração (Greenwood, Oliver, Lawrence, \& Meyer, 2017; Alvesson \& Spicer, 2019). Este texto visa, portanto, contribuir para reduzir essa lacuna por mais visões sociológicas que fundamentem estudos científicos na área, diante do seu potencial explicativo atestado (Franklin, 2009; Bispo, 2016; Lamers, Duim, \& Spaargaren, 2017).

Com efeito, os insights provenientes dessa articulação de conceitos visam agregar aos estudos sobre gestão do turismo, a fim de impactar e transformar os locais e comunidades onde ocorrem a atividade turística, a partir de aspectos socioculturais - a exemplo da construção de uma identidade turística -, potencializando, assim, o aproveitamento turístico de determinada localidade (Evans, 2009; Zucco, Quadros, Schmitt, \& Fiuza, 2017).

Argumenta-se aqui que, para obtenção de legitimidade dentro do campo organizacional do Turismo, um lugar precisa construir uma identidade a partir do potencial de seus atrativos, considerando atributos como "centralidade", "distintividade" e "durabilidade" que a legitimem no campo organizacional do qual faz parte. Dessa feita, a identidade organizacional é algo socialmente construído no tempo-espaço, e não aleatória ou fortuitamente decorrente; consequentemente, a identidade turística também é um processo de construção que acontece de forma gradativa, mediante a apropriação dessa identidade pelos diversos atores que formam o campo organizacional, sejam eles do setor público, privado ou do terceiro setor (Martins, 2003; Carrieri, Saraiva, \& Pimentel, 2008; Glynn, 2008; Lok, 2010; Brown, 2015). 


\section{APRESENTANDO OS CONCEITOS}

\section{A Atividade Turística}

O turismo é um fenômeno complexo e dinâmico, uma vez que seu campo de estudo é desenvolvido no tempo e no espaço, tanto por indivíduos quanto por grupos, e sua abrangência vai além das relações de consumo e mercado. Seus fundamentos circundam os anseios, necessidades e desejos humanos, envolvendo motivações psicológicas e também sociais em que, quem viaja, busca vivenciar experiências e também as compartilhar por meio dos souvenires, fotografias e lembranças (Panosso Netto \& Castillo Nechar, 2014).

Cada vez mais o turismo tem se tornado uma atividade que coloca o visitante como protagonista da viagem realizada, em que ele busca experienciar momentos marcantes e únicos provenientes de sua vivência turística, fugindo de aspectos convencionais da atividade turística, superando assim as expectativas pré-viagem. Dessa forma, o turista não tem interesse apenas na contemplação passiva dos atrativos, mas ir além daquilo que lhes é mostrado, participando dos bastidores dos lugares que estão visitando, contribuindo, inclusive, com a construção da identidade turística local (Oh, Fiore \& Jeoung, 2007; Panosso Netto \& Gaeta, 2010).

0 turismo está relacionado a questões de viagens, eventos, hospitalidade, lazer, cultura, meio ambiente, entre outras, e possui três perspectivas principais de interpretação, que se complementam, configurando a atividade turística. A primeira delas envolve entendê-lo sob: (i) uma visão leiga, na qual ele é tido como uma maneira de descanso ou de conhecer novos lugares apreciando boa comida, fugindo do estresse, como se estivesse recebendo um prêmio após um longo período de trabalho; (ii) uma visão empresarial, em que se percebe o turismo como oportunidade de obter lucro e renda, gerando riquezas para a localidade onde ele se instala, elaborando produtos/serviços que se tornarão ofertas a serem consumidos pelos viajantes; e (iii) uma visão acadêmico-científica, segundo a qual o turismo está relacionado ao desenvolvimento de ações que possam minimizar os impactos negativos e maximizar os positivos de determinada localidade, relacionando tal atividade à inclusão social, implantando políticas públicas que envolvam aspectos econômicos, políticos, culturais, sociais e ambientais (Panosso Netto, 2010).

Com a finalidade de auxiliar na padronização de dados estatísticos do turismo entre os países do mundo, a Organização Mundial do Turismo (OMT) uniformizou critérios definindo "Turismo" como as atividades desenvolvidas pelas pessoas durante suas viagens e estadas em lugares diferentes ao seu entorno habitual, por um período consecutivo inferior a um ano, com a finalidade de lazer, negócios ou outros motivos (Sancho, 2001). Em 2008, em publicação da IRTS (Recomendações Internacionais para as Estatísticas de Turismo), a OMT, junto à ONU, convencionou que "o turismo é um fenômeno social, cultural e econômico, que envolve o movimento de pessoas, para lugares fora do seu local de residência habitual, geralmente por lazer" (Pakman, 2014, p.18).

Jafari e Ritchie (1981), por sua vez, apresentam uma definição holística de turismo como sendo o estudo do homem longe do seu local habitual de residência, assim também como da indústria que satisfaz suas necessidades nesse ambiente, e dos impactos que ambos (ele e a indústria) geram sobre os ambientes físico, econômico e sociocultural da localidade receptora. 
De uma maneira mais ampla, considerando não apenas o deslocamento, mas também o destino turístico, Barretto (1991) define que "o turismo é o fenômeno de interação entre o turista e o núcleo receptor e de todas as atividades decorrentes dessa interação" (Barretto, 1991, p. 43). De forma que se percebe a atividade turística como sendo formada por uma infinidade de relações que estão entrelaçadas dentro de um contexto social, atuando como produtores de uma experiência turística. É uma rede de operadores que envolve indivíduos, empresas, organizações públicas e setores não governamentais - todos participando de uma rede de atividades, construindo e complementando ligações entre si (Evans, 2009; Fong et al., 2018).

A governança em destinos turísticos surge como um entendimento das estruturas administrativas em que, por meio de processos, podem acarretar consensos em cenários conflituosos, trazendo ainda eficiência, eficácia, equidade, transparência, cooperação e legitimidade da participação social nas decisões coletivas. No turismo, não há um modelo único de governança que possa ser aplicado em todos os destinos turísticos, mas ela é desenvolvida a partir da sua realidade social, a que foi construída por seus atores organizacionais de acordo com seus investimentos, planejamentos e forma de se organizarem. São, portanto, as lógicas institucionais de cada campo que definirão sua identidade (Bruyn \& Alonso, 2012; Gomes et al., 2014; Coutinho \& Nóbrega, 2019).

Existem quatro grupos de atores que, usualmente, estão diretamente relacionados à atividade turística: (i) as empresas de bens e serviços turísticos (meios de hospedagem, parques de diversão, casas de show etc.); (ii) os organizadores de viagens (operadoras de viagens que montam os pacotes de viagem, articulando as negociações entre as empresas de bens e serviços); (iii) os distribuidores dos produtos, serviços e pacotes (empresas que vendem os produtos ao consumidor final); e, (iv) os órgãos governamentais e demais organizações (gestores públicos e órgãos não-governamentais como associações e sindicatos) que, não necessariamente, criam ou comercializam produtos, mas se envolvem na gestão do turismo (Panosso Netto, 2010).

Algumas categorias foram determinadas dentro da atividade turística para que ela seja melhor compreendida. A oferta turística é o conjunto de elementos que formam o produto turístico que, por sua vez, é formado pelos atrativos, equipamentos e serviços turísticos, e infraestrutura de apoio ao turismo. Quanto maior e melhor a oferta turística de um destino, mais ele terá destaque dentro da atividade turística. Os atrativos podem ser naturais ou construídos, embora a OMT defina que é necessária alguma intervenção humana para consolidação do atrativo, pois, um recurso natural, em sua forma original, é considerado um atrativo potencial ou recurso turístico, sendo matéria-prima para futuros atrativos (Sancho, 2001; Oliveira, Minasse \& Marques, 2015).

Um dos princípios básicos de um destino turístico é que ele possua alguma atratividade que servirá de motivação para que as pessoas o visitem e, por sua vez, consumam todos os demais produtos/serviços que estão sendo oferecidos, sejam nos setores de hospedagem, alimentação ou de entretenimento. 0 atrativo turístico necessita de uma identidade que o diferencie dos demais, que o confira algum significado, sendo a identidade um atributo determinante para que um lugar seja classificado como turístico. Para que um destino consiga atuar na atividade turística, é preciso que elabore uma diretriz clara sobre o turismo que quer 
desenvolver, ou seja, que estabeleça critérios de "centralidade", "distintividade" e "durabilidade" no tempo (Panosso Netto, 2010).

Fatores como mão-de-obra qualificada, segurança, cuidados com a preservação do meio ambiente e, ainda, infraestrutura, permitem uma maior competitividade para os destinos turísticos, proporcionando mais chances de desenvolvimento, já que os destinos não podem se confiar apenas em suas belezas naturais, mas precisam, também, oferecer algum serviço de qualidade. Se a atividade turística não é planejada, o turismo não proporciona benefícios à localidade, mas pode contribuir para com a degradação ambiental, deslocamento de comunidades locais e criar condições precárias de emprego. Decorre daí a importância da implementação de estratégias, políticas e regulamentações, a fim de evitar impactos negativos ambientais e sociais e proporcionar o crescimento econômico (Franklin, 2009; Cárdenas- Garcia et al., 2015).

\section{A Construção Social da Realidade}

Aideia de "construção social" teve seus fundamentos oriundos de várias áreas: da Filosofia, da Ciência Política, da História e da Sociologia do Conhecimento, em que se buscava, principalmente, explicar a ação coletiva em diferentes realidades. A Sociologia do Conhecimento passou a existir a partir de questionamentos sobre a visão da ciência a respeito da neutralidade do contexto social-histórico para a produção de conhecimento. Devido ao "construcionismo social" ser um conceito da Sociologia do Conhecimento, várias áreas se apropriaram dele, buscando entender seus fenômenos próprios, entre elas a Psicologia Social. Nos Estudos Organizacionais, o Construcionismo Social influenciou de maneira significativa, concebendo que as organizações também são socialmente construídas, considerando importante o conhecimento do senso comum - e não apenas o conhecimento científico -, e as formas de sua produção e reprodução (Cunliffe, 2008).

A contribuição de Berger e Luckmann, em sua primeira edição de 1966, com a obra "A Construção Social da Realidade" foi determinante para edificar a noção de construção social (Berger e Luckmann, 2003). Seu principal pressuposto é o de compreender a realidade como um processo de construção promovido a partir das relações entre os indivíduos e a sociedade, considerando os significados e as interpretações de regras, hábitos e lógicas pertinentes a tais interações. Portanto, interesses, motivos, ideias - assim também como a identidade - não são elementos dados, oriundos de influências externas, mas construídos pela reflexão de como os indivíduos percebem o mundo, importando, assim, a forma como os atores se adaptam aos contextos em que vivem.

A realidade é algo intersubjetivamente construído pelos indivíduos, havendo uma contínua correspondência entre os significados partilhados nas relações sociais. Dessa forma, a Sociologia do Conhecimento proposta pelos autores trata da construção social da realidade, que se baseia nas relações entre o pensamento humano e o contexto social do qual ele surge, se ocupando daquilo que os indivíduos consideram como "realidade" em seus cotidianos teóricos e práticos, tendo no senso comum o seu foco central, constituindo os significados da sociedade (Berger \& Luckmann, 2003). 
À medida que se estabelece uma repetição em que se obedece a um padrão preestabelecido como certo (taken-for-granted), constitui-se um hábito e ações habituais são definidas pelos significados que são designados a elas. Esses processos habituais precedem a institucionalização de uma realidade tipificada reciprocamente pelos atores sociais que a vivenciam. Essa tipificação é exteriorizada e, assim, apreendida enquanto tipificada, havendo sua assimilação pelos diversos atores que compõem uma realidade. Com a exteriorização, essa realidade passa a ser objetificada. A fase da objetivação passa a um segundo estágio, a partir do momento em que novos significados se integram aos existentes, legitimando essa realidade. A exteriorização e a objetivação compõem um processo dialético contínuo, antecedente à interiorização, que configura um acúmulo do conhecimento da realidade, cristalizando-a (Berger \& Luckmann, 2003).

A partir dessas concepções, pode-se entender conceitos como os de "legitimação" e o de "institucionalização", que é construída por três fases: a exteriorização, a objetivação e a interiorização, em que "a sociedade é um produto humano. A sociedade é uma realidade objetiva. 0 homem é um produto social” (Berger \& Luckmann, 2003, p. 87). Por ser um processo, a institucionalização não necessariamente é algo irreversível, mas passível de mudanças, pois, se o mundo social é construído pelos indivíduos, também pode ser refeito por eles. Portanto, a construção social é um processo constante - nunca acabado, sempre "in the making".

Os processos de institucionalização relacionam-se aos conceitos do Construcionismo Social de Berger e Luckmann, principalmente, a partir dos estudos de Tolbert e Zucker (1997), considerando a institucionalização não como um resultado - em que estruturas são entendidas, binariamente, como institucionalizadas ou não -, mas sim como um processo em que práticas são inseridas e se tornam rotineiras e padronizadas nas organizações, mediante uma habitualização. Em seguida, acontece um processo de objetificação, onde os significados dessas práticas generalizam-se, expandindo-se para além de sua origem, e sendo repetidos em diferentes contextos, ocasionando, então, uma sedimentação dessas práticas, institucionalizando-se (Tolbert \& Zucker, 1997).

\section{O Institucionalismo Organizacional}

O institucionalismo organizacional é uma lente teórica do campo dos Estudos Organizacionais que busca explicar fenômenos nas organizações, analisando suas estruturas e ações, e como essas se legitimam, ocasionando consequências nos resultados planejados (Greenwood, Oliver, Sahlin, \& Suddaby, 2008). Ela busca explicar os processos de transformação das práticas organizacionais e de gestão enquanto reflexos de pressões sociais, apontando que as mudanças que ocorrem são respostas das organizações a essas forças, buscando estar em conformidade e legitimidade para, a partir disso, obterem o desempenho desejado. As organizações se posicionam interagindo e compondo um campo organizacional que, ao reforçarem uma ideia, a institucionalizam e legitimam, condicionando restrições, definindo limites legais, morais e culturais, estabelecendo o que podem ser comportamentos aceitáveis e inaceitáveis, fornecendo, ainda, estímulos, diretrizes e recursos para a ação dos indivíduos e/ou de organizações (Lawrence \& Suddaby, 2006; Scott, 2014). 
A teoria institucional de base sociológica estuda a sociedade por meio de suas instituições, em seus elementos reguladores, normativos e cultural-cognitivos que, juntamente com comportamentos e recursos diversos, proporcionam estabilidade e sentido à vida social, sendo formadas por indivíduos e suas interações - regras, normas e significados surgem em interação e são preservados e modificados pelo comportamento humano (Scott, 2014).

Os primeiros temas tratados pelo institucionalismo organizacional destacavam questões como os "campos organizacionais" e a "legitimidade", e o foco era a similaridade das organizações e os fatores normativos, coercitivos e cognitivos que as induziam a esse isomorfismo - considerando os arranjos institucionais e as conexões entre instituições, campos e organizações. Uma segunda fase dos estudos pautados pela lente institucionalista buscou compreender o papel dos atores na criação, efetivação, manutenção e/ou transformação de campos, utilizando conceitos que lidam com a agência dos atores institucionalmente imersos, realizando estudos sobre "lógicas institucionais", "empreendedorismo institucional" e "trabalho institucional", temas que dão relevância à natureza agêntica de indivíduos e organizações (Lawrence \& Suddaby, 2006; Greenwood et al., 2017).

Assim, além de estudar as relações entre as organizações e os campos em que estão inseridas, a perspectiva institucionalista também se interessa pelo comportamento organizacional em campos sociais, no qual processos institucionais governam a ação e a conduta humana cotidiana (Lawrence, Suddaby, \& Leca, 2009; Zietsma \& Mckinight, 2009). Machado-da-Silva, Guarido Filho e Rossoni (2006) definem que os campos organizacionais se caracterizam a partir da ação dos atores, e pelas relações entre a estrutura e os agentes envolvidos, onde se analisam os processos sociais e arranjos institucionais importantes na formação da ação organizacional. Os atores desse campo atuam como uma comunidade de organizações que participam de um sistema de significados comuns, interagindo com frequência.

Os ambientes organizacionais são estruturados de forma que as organizações incorporem elementos de outras, copiando processos ou aspectos que possam trazer maior visibilidade, competitividade, ou unidade, algo que irá legitimá-las frente a seu campo organizacional (Greenwood et al., 2017). Essa moldagem das organizações geralmente acontece por seus objetivos e procedimentos serem construídos diretamente na sociedade enquanto regras institucionais que induzem as demais a se adaptarem a elas. Uma vez que as organizações atuam dentro da sociedade, a legitimidade incorre numa percepção de que as ações de uma organização ou instituição são desejáveis, adequadas ou apropriadas dentro de um sistema socialmente construído de normas, valores, crenças e definições (Deephouse, Bundy, Tost, \& Suchman, 2017).

Surgem, então, mitos, regras e cerimônias pelas quais as organizações se legitimam, levando um grupo específico a utilizar os mesmos procedimentos, estabelecendo padrões, surgindo certa homogeneização das organizações, criando condutas únicas etc. (DiMaggio \& Powell, 1983). Logo, considera-se que as organizações são socialmente construídas a partir de padrões de adaptação e persistência institucionais, em que fenômenos são produzidos como resposta às instabilidades dentro e fora das organizações. Essa adaptação a fatores sociais e às mudanças foge, muitas vezes, de padrões burocráticos existentes. Por isso, a estrutura formal das organizações deve ser vista sempre como em adaptação, por aquelas serem sensíveis às influências ambientais, culturais e de legitimidade (Selznick, 1996). 


\section{A Identidade Organizacional}

"Identidade" tornou-se um dos principais conceitos dos Estudos Organizacionais e sua importância tem ficado mais aparente nos estudos em níveis macro de análise, que são aqueles que abordam, não a identidade individual na organização, mas, a identidade da própria organização em si, e como ela é identificada no campo que faz parte. É a relevância da identidade organizacional, que, inclusive, proporciona a aproximação entre os estudos de identidade e os estudos institucionalistas (Gioia, Patvardhan, Hamilton, \& Corley, 2013). Um dos principais estudos sobre identidade organizacional é baseado no trabalho de Albert e Whetten, de 1985, em que atributos definem a identidade de uma organização: a "centralidade" (que define a organização para os membros que a compõem); a "distintividade" (que a posiciona entre as outras organizações); e, a "durabilidade temporal" (que caracteriza o aspecto contínuo da organização) (Whetten, 2006).

Os atributos de Albert e Whetten são corroborados pela teoria do processo de identidade de Breakwell (1986), que sugere quatro princípios formadores da identidade local - estabelecimento de um senso de distinção (distintividade); senso de continuidade e preservação de seus conceitos (temporalidade); a autoestima; e a autoeficácia como sendo uma avaliação positiva de si mesmo e com aquilo que acredita (centralidade), em que a identidade local é vista como um produto dinâmico, fruto de uma construção processada pela interação das relações vivenciadas pelos residentes (Gu \& Ryan, 2008; Wang \& Chen, 2015).

Assim, as reivindicações de identidade legitimam-se quando elementos organizacionais resistem ao tempo, de modo que as características que conseguem se perpetuar como centrais e distintivas de uma organização são aquelas consideradas definidoras de sua identidade. Sendo assim, atributos centrais, duradouros e distintivos funcionam como referências definidoras da identidade e possuem funções de estruturação da organização (Asforth \& Mael, 1996; Whetten, 2006). A visão estratégica, por sua vez, aborda a identidade como um diferencial que pode ser utilizado na busca pela competitividade entre as organizações, podendo atuar como um filtro capaz de interpretar e responder às mudanças contextuais e outras questões estratégicas. Nisso, tanto a identidade pode atuar apoiando um posicionamento estratégico, como a estratégia pode servir de substrato para a definição da identidade organizacional (Gioia, Schultz, \& Corley, 2000; Glynn, 2008).

A identidade, portanto, define a existência organizacional, distinguindo-a de outras organizações, definindo quem ela é, quais suas ações e qual sua razão de existir. A agência atribuída aos atores é um processo de engajamento social em que os indivíduos, imersos em contextos culturais, socioestrutural e social-psicológico vão reavaliando, moldando e reconstruindo, numa perspectiva temporal, a realidade em que estão inseridos. Um sistema de significados é construído num determinado grupo, à medida que normas, valores, crenças e definições vão se sedimentando mediante suas ações. Este é um processo moldado por estruturas culturais externas que são interpretadas internamente, formando uma identidade que, pouco a pouco, vai sendo institucionalizada (Scott, 2014).

Com a finalidade de compreender como a identidade organizacional é formada, Selznick (1972) aponta quatro aspectos. 0 primeiro deles é sua tangibilidade 
através de decisões críticas e compromissos políticos, podendo ser observada dentro da linha histórica da organização. 0 segundo é a complexidade e a fungibilidade da identidade organizacional, podendo ser mutável a partir das influências externas e internas que surgem. 0 terceiro é o papel dos atores da organização, pois afetam, de maneiras diferentes, o processo de institucionalização. Por fim, o quarto aspecto é o caráter normativo e prescritivo em que se deve registrar, tal qual um guia, os processos de institucionalização. Dessa feita, a partir da análise da trajetória histórica da organização, verificando os compromissos e decisões que formam o seu caráter, é que se pode compreender o processo identitário que vai institucionalizando sua própria identidade, a qual é resultado dele.

\section{LEGITIMANDO UM DESTINO TURÍSTICO}

Os estudos institucionalistas têm abordado as populações de organizações dentro de um campo organizacional, suas interações, e a forma como elas afetam as instituições. Esses campos são caracterizados por regras implícitas que garantem o interesse e a ação dentro dele - ou seja, as lógicas institucionais que, com suas suposições e valores subjacentes, constituem o comportamento das organizações a partir da interpretação dessas acerca da realidade social em que estão inseridas (Lok, 2010). Mediante a participação e, principalmente, a cooperação de diversos atores sociais, é possível delinear ações e condutas de maneira descentralizada e participativa que possibilitarão a ampliação dos valores locais, entre eles, a identidade, em que tanto o Estado como os demais atores que formam o campo organizacional do turismo desempenham papéis que se articulam, potencializando os resultados da atividade turística (Endres \& Packman, 2019).

Pode-se considerar que a atividade turística configura o que o institucionalismo organizacional conceitua como um "campo organizacional" - um espaço comunicacional e de transação de bens simbólicos e materiais entre diferentes atores sociais, delimitando valores, normas, sanções e outros aspectos que derivam da sua associação -, pois, para que a prática do turismo aconteça, é necessária a ação de atores diversos, dos setores público e privado, trabalhando conjuntamente (Soica, 2016; Lamers et al., 2017). É no campo organizacional que pode ser observada a influência simultânea de diversos atores sociais que se utilizam de múltiplas práticas. Dessa forma, a realidade social é marcada por diversas lógicas que podem ser trabalhadas e combinadas, coadunando uma identidade própria. Esse conjunto de lógicas, por sua vez, oferece aos indivíduos e às organizações recursos que possibilitam transformar e criar identidades, ao passo em que vão se legitimando (Thorton, Ocasio, \& Lounsbury, 2012; Teixeira \& Roglio, 2015; Fong et al., 2018).

Yazigi (2002) pontua a importância da identidade local para a atividade turística, pois considera que ela cria uma personalidade ao destino em que o conceito de "identidade" se mistura ao de "lugar". Construir uma identidade é dar uma forma que legitime sua existência, e amplie o seu conceito considerando características geográficas, institucionais, sociais, culturais e econômicas. A identidade é algo construído socialmente por meio dos significados partilhados nas relações sociais. A construção desse processo identitário acontece em graus variáveis de deliberação e consciência, mas, também, de forma direta, 
a partir do interesse dos atores que trabalham inseridos num campo organizacional, e que objetivam desenvolver mecanismos que possibilitem sua construção. Assim, o trabalho identitário é uma forma de trabalho institucional entre os atores dentro do campo organizacional onde ele se encontra (Lawrence \& Suddaby, 2006; Brown, 2015). Dessa forma, a construção social da identidade organizacional vai desde uma dimensão sociológica até sua caracterização como uma lógica de mercado, em que um produto deve possuir marcas próprias que o diferencie dos demais e, por isso, desperte o interesse do consumidor (Glynn, 2017). Nisso, a exemplo de outras localidades do mundo, para uma cidade se tornar um destino turístico, ela necessita, além da divulgação de seus atrativos, da sua legitimação como tal (Zucco et al., 2017).

Esse processo de legitimação diz respeito a uma aceitação não apenas local (em termos dos indivíduos que ali residem ou, ainda, das organizações que ali existem), mas do trade que vende o destino turístico e, também, da comunidade de turistas que visitam o lugar e identificam, ali, características que o tornam interessante a ponto de ser visitado. A legitimidade é considerada um elemento-chave na imagem de um destino turístico, potencializando seu desenvolvimento, maximizando os impactos positivos que a atividade turística oferece. À medida que essa legitimidade é alcançada, por meio da apropriação da identidade local, esse destino passa a ser mais valorizado para a prática da atividade turística (Falaster et al., 2017).

Uma vez que os turistas têm buscado vivenciar a realidade dos destinos visitados, utilizando da experiência turística não apenas como uma apreciação/contemplação, características identitárias locais se fortalecem, pois, a visita se baseia em conhecer as particularidades das comunidades visitadas de um modo experiencial. A identidade turística assim, passa a considerar não apenas os componentes físicos (monumentos, praias, prédios ou infraestrutura) mas, também, seus usos, significados, valores e sentimentos da comunidade receptora (gastronomia, costumes). Os residentes, por sua vez, entendem a importância do turismo para o fomento econômico, mas, para isto, se faz necessária sua participação no processo, devendo os planejadores do turismo colocar os interesses e preferências da comunidade local de modo prioritário, valorizando seus atributos identitários (Panosso Netto et al., 2010; Wang et al., 2015).

Numa construção social, são utilizados quadros legitimadores, já institucionalizados, que garantam a adesão de indivíduos. Dessa forma, os atores sociais, por meio do trabalho institucional, utilizam as lógicas culturais e as configurações institucionais para construir novos arranjos institucionais, fornecendo significados e identidades comuns que viabilizem mudanças no cenário existente. Mesmo que as práticas, e a maneira de existir das organizações, estejam legitimadas - e, potencialmente, institucionalizadas -, o fato de as organizações estarem socialmente imersas na pluralidade cultural pode levá-las a mudanças de suas lógicas já instituídas (Creed, Scully, \& Austin, 2002).

A observação da interação prática de atores dentro de um campo organizacional que se orientem pelas pressões sociais externas possibilita a observação da construção social dessa identidade. As lógicas institucionais são, portanto, estruturas de referência pelas quais os atores atuam construindo o sentido do campo organizacional, como também sua identidade, sendo moldadas pelo trabalho institucional, elas compreendem princípios organizadores 
para ordens amplas e suprarracionais. Nesse contexto de lógicas institucionais e de identidades, tem-se que o conceito de identidade é de importância central para se entender mudanças nas lógicas institucionais, porque a identidade é pensada para formar um elo importante entre a lógica institucional e o comportamento de indivíduos e organizações (Lok, 2010; Thorton et al., 2012; Glynn, 2017; Fong et al., 2018).

O planejamento turístico tem, em sua base, os atrativos que a localidade possui, e deve refletir o caráter intrínseco, distintivo e único do produto turístico a ser oferecido (Evans, 2009; Santos, Ferreira, \& Costa, 2014). Assim, baseado nos atributos da identidade de Albert e Whetten (1985), os atrativos turísticos refletem, portanto, a identidade turística. A identidade é fruto de um processo de construção social em que, mediante a interação da (inter)subjetividade e da relação entre os atores, vai sendo legitimada e, quando essa identidade está relacionada a um destino turístico, essa legitimação é uma forma de institucionalização dos elementos simbólicos desse local, no campo organizacional turístico do qual faz parte (Palmer, 1999).

As instituições oferecem os símbolos e significados que constroem as identidades, agindo como uma "bricolagem institucional", inserindo nas organizações partes que se (re)combinam, criando uma distinção ideal. Essa "bricolagem institucional" baseia-se na necessidade de as organizações considerarem suas histórias - ou, muitas vezes, exemplos de sucesso - no campo organizacional para construir sua identidade, sendo um misto de comportamento isomórfico e distintividade. As organizações reúnem partes de elementos e símbolos culturais já institucionalizados como se formassem uma nova peça a partir de outras peças que consideram importantes para, assim, comporem uma identidade com atributos centrais e distintivos, a partir de elementos institucionalizados (Glynn, 2008; Besharov \& Brickson, 2016; Xue, Kertetter, \& Hunt, 2017).

Figura 1 - Construção Social da Identidade Turística

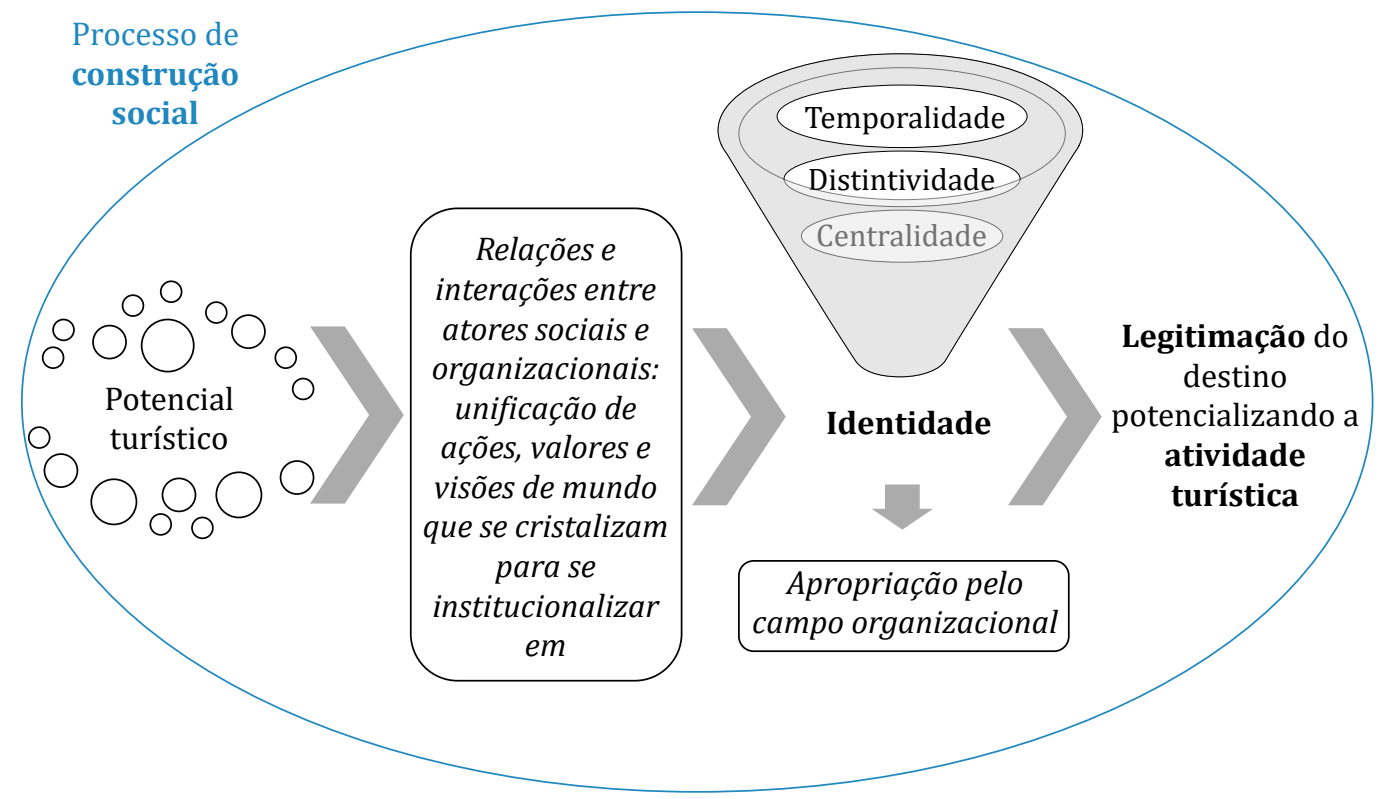

Fonte - Elaborado pelos autores 
Conforme sugere a Figura 1, uma localidade pode possuir um potencial capaz de atrair visitantes, não sendo considerado, por si só, um destino turístico. 0 processo de construção social da identidade ocorre por meio da interação das relações entre indivíduos - interpretando, moldando, fazendo e atribuindo sentido a algo, que ações, valores e visões de mundo se cristalizam, compondo assim atributos de centralidade, distintividade e temporalidade que definirão a identidade turística que, por sua vez, irão conferir legitimidade ao destino, potencializando assim, a atividade turística local.

As influências internas partem dos membros que atuam num continuum entre sensemaking (interpretar, fazendo sentido de algo) e sensegiving (moldar, atribuindo sentido a algo), compartilhando entendimentos, construindo (socialmente) a identidade, desempenhando um papel fundamental na construção, manutenção e adaptação da identidade da organização. Narrativas - que são algo compartilhado -, por exemplo, permitem aos membros de uma organização desenvolverem uma identidade comum, assim como representações, tais quais políticas e práticas organizacionais (Glynn, 2008; Besharov \& Brickson, 2016; Xue, Kersttter, \& Hunt, 2017). Os atores estão constantemente envolvidos, analisando as alternativas de ação e, ao mesmo tempo, reproduzindo ações já tomadas como certas (taken-for-granted), não sendo dois lados opostos, mas sim um continuum entre processos de tomada de decisão e comportamentos (Tolbert \& Zucker, 1997).

O processo de legitimação das organizações por meio da institucionalização da identidade pode ocorrer por três abordagens distintas: (i) a institucionalização como consequência da identidade; (ii) a identidade como sendo resultado da institucionalização; e (iii) a identidade como sendo o processo de institucionalização dentro de um campo institucional (Glynn, 2017). A identidade torna-se causa da institucionalização quando ela está presente no início das organizações, servindo de base para o processo de legitimação (Glynn, 2017); ela é considerada consequência da institucionalização nos casos em que uma instituição envolve a organização, imergindo-a numa identidade, infundindo valores e significados que a caracterizará (Selznick, 1972). A identidade é mecanismo nos processos de institucionalização dentro de um campo organizacional quando, por meio de pressões miméticas, coercitivas ou normativas, provoca um movimento da organização em assemelhar-se a outras, com o objetivo de se legitimar (DiMaggio \& Powell, 1983).

É importante ressaltar que estudos do turismo têm verificado que a formatação de atrativos turísticos é construída pela consolidação de atributos identitários que, ao estarem compatíveis com a construção cognitiva - pela comunidade local - de sua identidade, propiciará maior legitimidade e desenvolvimento turístico. Dessa feita, o papel dos moradores locais é determinante para as mudanças no campo, uma vez que a identidade turística depende, majoritariamente, da apropriação dos residentes, para que se consolide enquanto mercado turístico (Gu et al., 2008; Wang et al., 2015).

É necessário, portanto, compreender melhor a dinâmica entre a identidade e as forças institucionais, pois, essas podem aumentar, também, a capacidade de resposta dos membros a sua influência, reafirmando a ideia de que a identidade funciona como filtro interpretativo ante as forças institucionais, verificando uma melhor adequação das práticas organizacionais a essas influências, garantindo sua legitimidade no campo. Uma identidade forte, consolidada, por si só, pode influenciar ativamente na interpretação e modificação das demandas (Besharov \& Brickson, 2016). 


\section{CONSIDERAÇÕES FINAIS}

Sustenta-se, com esse ensaio, que a identidade é fruto de um processo de construção social em que, mediante a interação da (inter)subjetividade e da relação entre os atores, vai sendo legitimada. A identidade turística de determinada localidade é caracterizada pelos atrativos turísticos que ela possui - promulgados, veiculados, comercializados, publicizados e mercadorizados por organizações enquanto partes interessadas (stakeholders) daquele ecossistema -, uma vez que, a partir de suas diretrizes definidas, condicionam ações e comportamentos que maximizam sua utilidade, sendo moldados pelo cenário em que estão inseridos, se legitimando no campo organizacional do qual fazem parte, sobretudo, a partir dos sentidos e significados identitários que vão se atrelando a ela.

A relação entre o turismo e a identidade surge a partir da necessidade de o destino visitado possuir uma significação e, assim, tornar-se atraente à visitação (Palmer, 1999; Soica, 2016; Zucco et al., 2017). A identidade é abordada nos estudos turísticos não como movimento para construí-la, mas para preservá-la. No caso, identidade turística, não é o objetivo da prática profissional do turismo, mas, a sua existência fornece ao atrativo turístico a sua razão de existir. A construção identitária está relacionada à caracterização do atrativo em que os indivíduos que residem em um lugar com potencial turístico apropriam-se dessa identidade, carregando uma significação valorativa e emocional que os faz pertencer ao lugar, sentindo-se parte dele. Os atores que estão envolvidos na prática profissional do turismo percebem essa importância da identidade local, e podem atuar em sua preservação, a fim de buscar a legitimidade desse destino no campo organizacional do turismo (Martins, 2003).

0 presente ensaio buscou apresentar articulações entre a construção social da identidade e a atividade turística sob a ótica do institucionalismo organizacional, verificando que a identidade turística é um fator importante aos destinos, sendo necessária sua institucionalização para conferir-lhes legitimidade. Face ao exposto, afirma-se que essa lente teórica, de cunho sociológico, mostra-se com potencial oportuno para investigações científicas que se debrucem por tentar entender como ocorrem os processos institucionais que (re)constroem a identidade turística de determinada(s) localidade(s), fazendo convergir, com isso, elementos de gestão e organização significativos para estudos na Administração e no Turismo, uma vez que as organizações figuram entre os mais relevantes atores sociais da contemporaneidade (Scott, 2014; Powell \& Brandtner, 2016).

0 enfraquecimento dos atributos identitários - centralidade, distintividade e temporalidade - podem ocasionar transformações na prática turística de um destino, uma vez que a identidade é fruto de um processo de construção social da realidade, e este, por sua vez, é contínuo. Por meio da capacidade agêntica dos atores do campo, além de responder a influências externas ao contexto, pode tanto reforçar como modificar a identidade local. 0 turismo é um fenômeno fundamentado nas interações dos indivíduos, não obedecendo a padrões de ação que resultem em produtos iguais. Dessa forma, fatores e influências que circundam o campo poderão provocar respostas diferentes na construção de uma identidade turística.

Agendas futuras de pesquisa podem analisar os processos, mecanismos e trabalhos institucionais de construção identitária dos destinos turísticos, identificando as redes de relações entre os atores do campo organizacional, evidenciando 
o papel do indivíduo - turista ou morador local -, na legitimação ou deslegitimação dos atrativos. Para acessar e apreender tais processos eminentemente sociais, acredita-se que, em termos metodológicos, estudos que sigam abordagens e métodos qualitativos ou mistos sejam os mais adequados e promissores (Jennings, 2009; Wilson \& Hollinshead, 2015; Hillman \& Radel, 2018), dada a natureza experiencial e simbólico-cultural das práticas da gestão e do turismo (Palmer, 1999; Evans, 2009; Mintzberg, 2010; Suddaby, 2010; Bispo, 2016; Soica, 2016; Lamers et al., 2017). Pesquisas que se debrucem sobre

No que tange a contribuições práticas, o institucionalismo organizacional pode ser muito útil à prática profissional do turismo, auxiliando em âmbito governamental, direcionando políticas públicas a fim de perceber as melhores possibilidades de investimentos, considerando aspectos relevantes do trade, a partir de conceitos como o de legitimidade, bem como no âmbito do setor privado, ao se propor analisar as práticas utilizadas pelas organizações e seus alicerces em lógicas institucionais, podendo vislumbrar estratégias de se adaptar às mudanças que surgem no contexto em que estão inseridas, sendo essas apenas algumas das possibilidades de estudos futuros que se pautem pela lente institucionalista.

\section{REFERÊNCIAS}

Albert, S., \& Whetten, D. A. (1985). Organizational identity. Research in Organizational Behavior, 7: 263-295.

Alvesson, M., \& Spicer, A. (2019). Neo-Institutional Theory and Organization Studies: a mid-life crisis? Organization Studies, 40(2): 199-218.

Asforth, B., \& Mael, F. (1996). Organizational identity and strategy as a context for the individual. Advances in Strategic Management, 13: 19-63.

Barretto, M. (1991). Planejamento e Organização em Turismo. Campinas, SP. Papirus.

Berger, P. L., \& Luckmann, T. (2003). A construção social da realidade. Petrópolis: Vozes.

Besharov, M. L., \& Brickson, S. L. (2016). Organizational identity and institutional forces: toward an integrative framework. In Pratt, M. G., Schultz, M., Ashforth, B. E., \& Ravasi, D. (Ed.), The Oxford handbook of organizational identity. (pp. 396-414). New York: Oxford University Press.

Bispo, M. S. (2016). Tourism as practice. Annals of Tourism Research, 61: 170-179.

Breakwell, G. (1986). Coping with threatened identities. London: Methuen.

Brown, A. D. (2015). Identities and identity work in organizations. International Journal of Management Reviews, 17(1): 20-40.

Bruyn, C., \& Alonso, A. F. (2012). Tourism Destination Governance: guidelines of implementation. In Fayos-Solá, E., Silva, J.A.M., \& Jafari, J. (org.). Knowledge Management in Tourism: policy and governance applications. Bingley: Emerald.

Cárdenas-Garcia, P. J., Sánchez-Rivero, M., \& Pulido-Fernández, J. I. (2015). Does tourism growth influence economic development? Journal of Travel Research, 54(2): 206-221.

Carrieri, A. de P.; Saraiva, L. A. S. \& Pimentel, T. D. (2008). A Institucionalização da Feira Hippie de Belo Horizonte. Organizações \& Sociedade, 15(44): 63-79.

Cooper, C., Fletcher, J., Fyall, A., Gilbert, D., \& Wanhill, S. (2008). Turismo: princípios e práticas. (3. ed.). Porto Alegre: Bookman. 
Coutinho, A. C. A., \& Nóbrega, W. R. M. (2019). Governança em Destinos Turísticos: Desafios na Sociedade Contemporânea. Revista Brasileira de Pesquisa em Turismo, 13(3): 55-70.

Creed, W. E. D., Scully, M. A., \& Austin, J. R. (2002). Clothes Make the Person? The Tailoring of Legitimating Accounts and the Social Construction of Identity. Informs, 13(5), 475-496.

Cunliffe, A. L. (2008). Orientations to social constructionism: relationally responsive social constructionism and its implications for knowledge and learning. Management Learning 39(2): 123-139.

Deephouse, D. L., Bundy, J., Tost, L. P., \& Suchman, M. C. (2017). Organizational legitimacy: six key questions. In Greenwood, R.; Oliver, C.; Lawrence, T.; Meyer, R. E. (Ed.). The SAGE handbook of organizational institutionalism. (2. ed. pp. 27-54). London, Thousand Oaks, CA \& New Dehli: Sage Publications.

DiMaggio, P. J., \& Powell, W. W. (1983). The iron cage revisited institutional isomorphism and collective rationality in organizational fields. American Sociological Review, 48(2): 147-169.

Endres, A. V., \& Pakman, E. T. (2019). A governança das políticas de turismo: o papel dos espaços de participação na perspectiva da análise de redes e da Teoria Institucional. Revista Brasileira de Pesquisa em Turismo, 13(1):1-18.

Evans, N. (2009). Tourism: a strategic business perspective. In Jamal, T., \& Robinson, M. (Ed.). The SAGE handbook of tourism studies. (2. Ed, pp. 215-234). London, Thousand Oaks, CA \& New Dehli: Sage Publications.

Falaster, C., Zanin, L. M., \& Guerrazzi, L. A. (2017). Teoria Institucional na pesquisa em Turismo: novas oportunidades de uma teoria em evolução. Revista Brasileira de Pesquisa em Turismo, 11(2): 270-293.

Fong, V. H. I., Wong, I. A., \& Hong, F. L. J. (2018). Developing institutional logics in the tourism industry through coopetition. Tourism Management, 66: 244-262.

Franklin, A. (2009). The sociology of tourism. In Jamal, T., \& Robinson, M. (Ed.). The SAGE handbook of tourism studies (2. ed., pp. 65-81). London, Thousand Oaks, CA \& New Dehli: Sage Publications.

Gioia, D. A., Patvardhan, S. D., Hamilton, A. L., \& Corley, K.G. (2013). Organizational identity formation and change. The Academy of Management Annals, 7(1): 123-193.

Gioia, D. A., Schultz, M., \& Corley, K. G. (2000). Organizational identity, image, and adaptive instability. Academy of Management Review, 25(1): 63-81.

Glynn, M. A. (2008). Beyond constraint: how institutions enable identities. In Greenwood, R., Oliver, C., Sahlin, K., \& Suddaby, R. (Ed.). The SAGE handbookoforganizational institutionalism. (1. ed., pp. 413-430). London, Thousand Oaks, CA \& New Dehli: Sage Publications.

Glynn, M. A. (2017). Theorizing the identity-institution relationship: considering identity as antecedent to, consequence of, and mechanism for, processes of institutional change. In Greenwood, R., Oliver, C., Lawrence, T. B., \& Meyer, R. E. (Ed.). The SAGE handbook of organizational institutionalism (2. ed., pp. 243-258). Los Angeles: Sage.

Gomes, B. M. A., Vargas-Sánchez, A., \& Pessali, H. F. (2014). Interação empresários-setor público no Turismo: uma análise institucional e neocorporativista da cidade de Huelva (Espanha). Revista Brasileira de Pesquisa em Turismo, 8(3): 382-402.

Greenwood, R., Oliver, C., Lawrence, T. B., \& Meyer, R. E. (2017). Introduction: into the fourth decade. In Greenwood, R., Oliver, C., Lawrence, T. B., \& Meyer, R. E. (Ed.). The SAGE handbook of organizational institutionalism. (2. ed., pp. 1-23). London, Thousand Oaks, CA \& New Dehli: Sage Publications, 2017.

Greenwood, R., Oliver, C., Sahlin, K., \& Suddaby, R. (2008). Introduction. In Greenwood, R., Oliver, C., Sahlin, K., \& Suddaby, R. (Ed.). The SAGE handbook of organizational institutionalism. (1. ed., pp. 1-46). London, Thousand Oaks, CA \& New Dehli: Sage Publications. 
Gu, H., \& Ryan, C. (2008). Place attachment, identity and community impacts of tourism the case of a Beijing Hutong. Tourism Management, 29: 637-647.

Hillman, W., \& Radel, K. (2018). Qualitative methods in tourism research: theory and practice (Series - Aspects of Tourism: 82). Bristol, UK: Channel View Publications, 2018.

Jafari, J., \& Ritchie, J. R. B. (1981). Toward a framework for tourism education: problems and prospects. Annals of tourism research, 8(1): 13-34.

Jennings, G. R. (2009). Methodologies and methods. In Jamal, T., \& Robinson, M. (Ed.). The SAGE handbook of tourism studies. (2. ed., p. 672-692). London, Thousand Oaks, CA \& New Dehli: Sage Publications.

Lamers, M., Duim, R. V. D., \& Spaargaren, G. (2017). The relevance of practice theories for tourism research. Annals of Tourism Research, 62: 54-63.

Lawrence, T., \& Suddaby, R. (2006). Institutions and institutional work. In: S. R. Clegg, C., Hardy, T. B., Lawrence, W. R., \& Nord (Ed.). Handbook of organization studies. (pp. 215- 254). London: Sage.

Lawrence, T. B., Suddaby, R., \& Leca, B. (2009). Introduction: theorizing and studying institutional work. In Lawrence, T. B., Suddaby, R., \& Leca, B. (Ed.). Institutional work: actors and agency in institutional studies of organizations (pp. 1-27). Cambridge: Cambridge University Press.

Lok, J. (2010). Institutional logics as identity projects. Academy of Management Journal, 53(6), 1305-1335.

Machado-da-Silva, C. L., Guarido Filho, E. R., \& Rossoni, L. (2006). Campos organizacionais: seis diferentes leituras e a perspectiva de estruturação. Revista de Administração Contemporânea, 10(ed. esp.): 159-196.

Martins, C. (2003). Identidade: percepção e contexto. In Martins, J. C. O. (Org.). Turismo, cultura e identidade, (pp. 39-48). São Paulo: Roca.

Mintzberg, H. (2010). Managing: desvendando o dia a dia da gestão. Porto Alegre: Bookman.

Oh, H.; Fiore, A. M., \& Jeoung, M. (2007). Measuring experience economy concepts: tourism applications. Journal of Travel Research, 46: 119-32.

Oliveira, C., Minasse, M. H., \& Marques, S. (2015). Processo de Formatação de Atrativos Turísticos Sustentáveis. Revista Turismo em Análise, 26(3): 639-667.

Pakman, E. T. (2014). Sobre as definições de turismo da OMT: uma contribuição à História do Pensamento Turístico.Anais do Seminário da Associação Nacional Pesquisa ePós-Graduação em Turismo, Fortaleza, CE, Brasil, 9. Recuperado de: https://www.anptur.org.br/ anais/anais/files/11/34.pdf.

Palmer, C. (1999). Tourism and the symbols of identity. Tourism Management, 20(3), 313-321.

Panosso Netto, A. (2010). O que é turismo. São Paulo, SP: Editora Brasiliense.

Panosso Netto, A. \& Gaeta, C. (2010). Turismo de Experiência. São Paulo: SENAC.

Panosso Netto, A., \& Castillo Nechar, M. (2014). Epistemologia do turismo: escolas teóricas e proposta crítica. Revista Brasileira de Pesquisa em Turismo. São Paulo, 1(8): 120-144.

Pimentel, T. D., Carvalho, F. C. C., \& Pimentel, M. P. C. (2019). 0 processo de Institucionalização das estruturas formais de Investigação em Turismo (EFIT) no Brasil. Revista Brasileira de Pesquisa em Turismo, 13(3): 16-35.

Powell, W. W., \& Brantner, C. (2016). Organizations as sites and drivers of social action. In Abrutyn, S. (Ed.). Handbook of contemporary sociological theory (Handbooks of Sociology and Social Research series, 1. Ed., pp. 269-291). Switzerland: Springer International Publishers. 
Sancho, A. (2001). Introdução ao turismo. Organização Mundial de Turismo (OMT). São Paulo: Rocca.

Santos, M. M., Ferreira, A. M., \& Costa, C. (2014). Identificação dos recursos nucleares do destino como suporte para o desenvolvimento de produtos turísticos inovadores. Revista Turismo \& Desenvolvimento, 21(4): 315-330.

Scott, W. R. (2014). Institutions and organizations: ideas, interests, and identities. (4. ed.). London, Thousand Oaks, CA \& New Dehli: Sage Publications.

Selznick, P. (1972). A liderança na administração: uma interpretação sociológica. Rio de Janeiro: Fundação Getúlio Vargas.

Selznick, P. (1996). Institutionalism "old" and "new". Administrative Science Quarterly, 41(2): 270-277.

Soica, S. (2016). Tourism as practice of making meaning. Annals of Tourism Research, 61: 96-110.

Suddaby, R. (2010). Challenges for Institutional Theory. Journal of Management Inquiry, 19(1): 14-20.

Teixeira, M. G., \& Roglio, K. D. (2015). As influências da dinâmica de lógicas institucionais na trajetória organizacional: o caso da Cooperativa Veiling Holambra. Brazilian Business Review, 12(1): 1-37.

Thorton, P. H., Ocasio, W., \& Lounsbury, M. (2012). The institutional logics perspective: a new approach to culture, structure, and process. Oxford: Oxford University Press.

Tolbert, P. S., \& Zucker, L. G. (1997). A institucionalização da Teoria Institucional. In Clegg, S., Hardy, C., \& Nord, W. (Org.). Handbook de estudos organizacionais (v. 1, pp. 196-219). São Paulo: Atlas.

Valls, J. F. (2006). Gestão integral de destinos turísticos sustentáveis. Tradução: Cristiano Vasques e Liana Wang. Rio de Janeiro: Editora FGV.

Wang, S. \& Chen, J. S. (2015). The influence of place identity on perceived tourism impacts. Annals of Tourism Research, 52: 16-28.

Whetten, D. A. (2006). Albert and Whetten revisited - strengthening the concept of Organizational Identity. Journal of Management Inquiry, 15(3): 219-234.

Wilson, E., \& Hollinshead, K. (2015). Qualitative tourism research: opportunities in the emergent soft sciences. Annals of Tourism Research, 54: 30-47.

Xue, L., Kerstetter, D., \& Hunt, C. (2017). Tourism development and changing rural identity in China. Annals of Tourism Research, 66: 170-182.

Yazigi, E. (2002). A alma do lugar: turismo, planejamento e cotidiano em litorais e montanhas. São Paulo: Contexto.

Zietsma, C., \& Mckight, B. (2009). Building the iron cage: institutional creation work in the context of competing proto-institutions. In Lawrence, T. B., Suddaby, R., \& Leca, B. Institutional work: actors and agency in institutional studies of organizations (pp. 143-176). Cambridge: Cambridge University Press.

Zucco, F. D., Quadros, C. M. B., Schmitt, J. R., \& Fiuza, T. F. (2017). Imagem e identidade turísticas relacionadas às práticas e bens culturais percebidas pelos residentes: perspectivas a partir da cidade de Blumenau, Santa Catarina, Brasil. Revista Brasileira de Pesquisa em Turismo, 11(2): 320-346. 


\section{CONTRIBUIÇÃo}

Mariene Cavalcante Borba de Albuquerque: Definição do problema de pesquisa e objetivos, desenvolvimento da proposição teórica, realização da revisão bibliográfica e fundamentação teórica, escolha dos procedimentos metodológicos, elaboração de tabelas, gráficos e figuras, redação do manuscrito e adequação do manuscrito às normas da RTA.

Samir Adamoglu de Oliveira: Definição do problema de pesquisa e objetivos, desenvolvimento da proposição teórica, elaboração de tabelas, gráficos, figuras e revisão crítica do manuscrito e orientações e instruções ao desenvolvimento do manuscrito. 